\title{
Gestão em Saúde: um estudo sobre Comunicação e Participação Popular no contexto de uma Organização Pública
}

\author{
Health Management: A Study on Communication and Public Participation in the context of a Public Organization
}

\section{RESUMO}

Este artigo discute a comunicação dialógica para a criação de vínculos na relação entre organização pública e usuários. Pretende-se compreender como ocorrem os processos de comunicação, enfatizando a participação popular, diferentemente da simples adaptação mercadológica na gestão pública. A pesquisa foi feita em um Centro de Saúde de Belo Horizonte. Observou-se que a comunicação é desenvolvida a partir do modelo emissor-receptor e que há necessidade de se realizar uma comunicação dialógica, com base na troca e negociação.

Palavras-chave: Comunicação. Dialógica. Participação. Gestão pública. Saúde.

Paula Fernandes Furbino Bretas - paulaffb@gmail.com

Mestranda em Administração. CEPEAD/ FACE/ UFMG

Úrsula Fuscaldi Ferreira - ursulafuscaldi@gmail.com

PUC MINAS - Fundação Dom Cabral

Raquel Alves Furtado - raquelfurtado@gmail.com

Professora Doutora no Departamento de Administração da PUC Minas.

Artigo submetido no dia 23.08.2012 e aprovado em 18.11.2013

\section{Abstract}

This article discusses the dialogic communication that creates bonds between a public organization and its users. The aim is to understand how communication processes occur, emphasizing popular participation, which is different from the simple adaptation of business practices to public management. The research was developed at a health-care center in the city of Belo Horizonte. It was observed that the communication process there is based on the emitter-receiver model. However, dialogic communication based on exchange and negotiation should be developed.

Keywords: Communication. Dialogic. Participation. Public Management. Health. 


\section{INTRODUÇÃO}

O objetivo deste artigo é compreender como ocorrem os processos de comunicação entre a organização que presta serviços públicos de saúde e seus usuários. Este estudo inserese no campo da Administração Pública, na área temática que estuda as dimensões intraorganizacionais das organizações públicas bem como as relações micro da política de saúde, pois busca entender a comunicação em sua dinâmica estratégica no setor público, isto é, a comunicação como processo conduzido intencionalmente pelas organizações visando orientar ações ou decisões de forma articulada (OLIVEIRA; PAULA, 2012). Contudo, vale ressaltar a interdisciplinaridade do tema, uma vez que tem contribuições também para outros campos na medida em que discute a comunicação como processo constituinte das organizações (OLIVEIRA; PAULA, 2012), base das relações sociais.

Em revisão de autores estrangeiros, Haswani (2006) defende que a comunicação pública, enquanto estratégia, pode ser pensada em três vertentes: comunicação jurídica-formal, comunicação de serviços e comunicação administrativa ou de cidadania. Há de se pensar numa ampliação desses conceitos para uma abordagem da comunicação na gestão de organizações públicas de saúde brasileiras, tendo em vista que elas apresentam peculiaridades contextuais históricas. Considera-se necessário frisar as diferenças da gestão de organizações privadas, como 1) a relação com políticas públicas, 2) a necessidade de atendimento a demandas básicas da sociedade e 3) o relacionamento com a sociedade civil (SOARES; MONTEIRO, 2012). Diante das novas tendências por accountability, por exemplo, Soares e Monteiro (2012) defendem a combinação de dois processos de comunicação: informação e negociação. O primeiro, proporcionado pelo uso da publicidade, seria aliado a outras ações de comunicação para que não somente a organização se comunique com a sociedade, mas vice-versa. Assim, a comunicação é vista como processo e se manifesta de forma participativa e interativa (SOARES; MONTEIRO, 2012).

A construção de espaços dialógicos e relacionais, ou seja, a consideração de contextos e condicionamentos dos atores sociais relacionados, expande a visão mecanicista da comunicação (KUNSCH, 2003; OLIVEIRA, 2009). Atualmente hegemônico, o modelo informacional de comunicação, que considera um processo linear de transmissão de mensagens de um emissor para um receptor seria substituído por um modelo dialógico, pois se acredita que a ênfase aos polos neglicencia a natureza das mensagens e os sentidos produzidos (LIMA; BASTOS, 2012). Este último modelo condiz com um paradigma relacional da comunicação em que o processo de produção e compartilhamento de sentidos entre sujeitos interlocutores é sempre marcado pela situação de interação e pelos contextos social e histórico. Dessa forma, o papel da comunicação no contexto organizacional é mediação e organização dos processos de interação entre atores; todo estímulo é resposta e toda resposta é estímulo. Nessa concepção, os sentidos são escolhas do receptor, ou seja, é no receptor que a comunicação acontece (LIMA; BASTOS, 2012). Diante disso, as ações de comunicação e as atribuições de cada ator deveriam ser estabelecidas de forma dialogada e negociada, ancoradas em trocas fundamentadas nas experiências de cada ator. 
Para analisar a comunicação na gestão de organizações públicas de saúde, faz-se necessário uma contextualização do sistema norteador de saúde no Brasil: o Sistema Único de Saúde (SUS), que foi criado a partir da Constituição Federal do Brasil publicada em 5 de outubro de 1988, no Diário Oficial da União. A Constituição Federal, na seção II da saúde, estabelece que o governo deve garantir serviços de saúde a toda população brasileira a partir de políticas públicas definidas em seus artigos de 196 a 200 (BRASIL, 2007).

Em 19 de setembro de 1990, foi publicada a Lei Federal n. 8080, regulamentando em todo - Brasil as ações e os serviços de saúde bem como os direitos da população e os deveres do Estado. Menicucci (2009) faz uma avaliação dos 20 anos do SUS no país e como os avanços apontam um impacto substancial (cobertura de três quartos) na população, pois possui o maior número de estabelecimentos de saúde e é responsável pela maior parte dos procedimentos. "Da perspectiva da gestão, o SUS constitui um exemplo de pacto federativo democrático, no qual as ações são acordadas em instâncias formais com a participação das três esferas de governo e da sociedade." (MENICUCCI, 2009, p. 1623).

Em caráter municipal, a Prefeitura de Belo Horizonte tem dado destaque ao Programa Saúde da Família (PSF) do governo federal, que na capital mineira ganhou o nome de $\mathrm{BH}$ Vida. O Programa BH Vida foi implantado em Belo Horizonte entre 2000 e 2002, partindo da estratégia do PSF. Isso significa que o município atendeu as diretrizes do Ministério da Saúde quanto à formação de equipes multidisciplinares para atendimento da população, pensando em uma ótica de acompanhamento e prevenção da saúde coletiva em todo o território. A formação das equipes utilizava critérios de risco para determinar o número de pacientes inserido em cada grupo, cujos membros "passaram a atuar como profissionais e, em algumas circunstâncias, como equipes de apoio, participando do planejamento das ações das equipes às quais apoiavam, dividindo o trabalho, compartilhando responsabilidades." (PINTO; COELHO, 2010 , p. 6). O programa mudou a lógica do atendimento de saúde, com a promoção de visitas domiciliares e comunitárias que, mais do que diagnosticar doenças, previnem as suas causas (BELO HORIZONTE, 2010).

Em relação à comunicação no PSF, Cardoso e Nascimento (2010) indicam a que o agente de saúde é visto como um elo integrador entre a equipe e a comunidade, com potencial para facilitar a comunicação no âmbito local. Contudo, os resultados de sua pesquisa revelaram que a comunicação é percebida de forma verticalizada e com traços de autoritarismo, o que justifica a importância da ampliação do diálogo e da negociação. Nesse sentido, é fundamental buscar novos saberes e práticas para possibilitar a implementação do SUS e sua efetividade, de acordo com os preceitos constitucionais de universalização, descentralização, integralidade e participação social (CARDOSO; NASCIMENTO, 2010).

Este artigo está estruturado da seguinte forma: primeiro, é importante pontuar alguns conceitos de comunicação organizacional pública; logo, a participação popular e a mobilização social foram inseridas nesse contexto; segundo, apresentase a metodologia utilizada seguida das considerações finais que contêm os principais achados da pesquisa.

\section{COMUNICAÇÃO ORGANIZACIONAL}




\section{PÚBLICA}

Neste tópico, pretende-se discutir a comunicação como um processo estratégico. O conceito de comunicação pública, que, segundo Haswani (2007), ainda está em processo de construção, apresenta diversas abordagens. Para Matos (2006), a expressão comunicação pública apresenta basicamente três grupos de significação e sentido. Pode ser "invocado ora como utopia, ora como conceito renovado de comunicação governamental ou, ainda, como próximo passo nas relações comunicativas entre - Estado (não o governo) e a sociedade" (MATOS, 2006, p. 61).

Geralmente, a comunicação em órgãos públicos limita-se a divulgar propagandas de ações e sucessos governamentais. Contudo, neste artigo, adota-se um recorte diferente do tradicional. Reflexões contemporâneas acerca da comunicação apontam para uma nova forma de tratá-la, haja vista a insuficiência do paradigma emissorreceptor. França (2002) e Oliveira (2003a) ressaltam elementos que descrevem essa mudança, como a questão dos sujeitos interlocutores e do processo de produção em determinado contexto. Para os autores, os papeis de emissor e receptor perderam suas funções específicas de emitir e receber mensagens. Considerando todas as partes como interlocutores, "pressupõese uma predisposição para compartilhar informações e ideias no sentido de alcançar uma compreensão mútua daquilo que se quer atingir" (OLIVEIRA, 2003a, p. 4).

Em relação aos sujeitos, há uma atenção maior ao envolvimento deles na produção e interpretação de sentidos, rompendo a visão de simples emissores e receptores. Além disso, não há apenas um processo de transmissão de mensagens, mas também uma troca partilhada em que são considerados os contextos nos quais os atores estão envolvidos. (FRANÇA, 2002).

França (2002) afirma que "a especificidade do olhar da comunicação é alcançar a interseção das três dinâmicas básicas: o quadro relacional (relação dos interlocutores); a produção de sentidos (as práticas discursivas); a situação sociocultural (o contexto)".

Pode-se relacionar 0 processo de comunicação organizacional aos níveis e fluxos de comunicação. Para Kunsch (2003), a comunicação ocorre nos níveis intrapessoal, interpessoal, organizacional e tecnológico. Todos eles refletem as habilidades e dificuldades de um indivíduo no processo de comunicação, porque retrata como ele irá transmitir ou receber a mensagem. Classificados como ascendente, lateral, transversal e circular, os fluxos de comunicação são responsáveis por determinar como a comunicação será conduzida dentro da organização, a qual pode ocorrer pelos meios de comunicação tradicional e oral (face a face), impressos ou com recursos audiovisuais.

Atualmente, de acordo com Oliveira (2003a), o processo de comunicação organizacional só é considerado efetivo quando existe relacionamento entre a organização e seus públicos. O grau de relacionamento com o público está vinculado ao envolvimento dos públicos no processo. Dessa forma, destacase o papel do profissional de relações públicas dentro da comunicação, porque ele é responsável por criar um relacionamento com os componentes sociais e políticos de seu ambiente (FERRARI, 2008). 
Segundo Kunsch (2007), outro fator importante que justifica a preocupação das organizações em estabelecer uma comunicação que seja mais relacional, fugindo da perspectiva que visa à mera realização de ações paternalistas por meio das organizações, é a relevância estratégica dos públicos de uma comunidade para a instituição. França (2002) afirma que as reflexões contemporâneas têm indicado um novo caminho para o processo comunicacional, que se opõe ao paradigma clássico de emissor/ receptor.

A partir dessa perspectiva, a comunicação é entendida como "um processo de produção e compartilhamento de sentidos entre sujeitos interlocutores, realizado por meio de uma materialidade simbólica (da produção de discursos) e inserido em determinado contexto sobre o qual atua e do qual recebe os reflexos" (FRANÇA, 2002, p. 27).

No paradigma relacional da comunicação, os elementos que constituem o processo comunicativo se inter-relacionam de forma dinâmica, buscando a circularidade e globalidade do processo, que possibilitam a intervenção de sujeitos sociais, interação, ações partilhadas e processos de troca (FRANÇA, 2002).

Em uma das contribuições referenciadas por Haswani (2006), é defendida a ideia de que as instituições públicas devem se preocupar em informar os cidadãos, prezando pela transparência, e promover a inovação institucional. Para tanto, são apontados como elementos fundamentais no processo da relação social (instituição pública e cidadão) a informação dos próprios funcionários e o reconhecimento do cidadão como ator social, capaz de contribuir e participar de mudanças (HASWANI, 2006).
A participação dos cidadãos é uma questão chave no conceito de governança democrática que emergiu no Brasil, na década de 1980, a partir dos ideais de reforma das instituições de governo local. Segundo Novelli (2006), a prática da governança democrática pode ser realizada a partir de instrumentos de 1) democracia direta (referendo, plebiscito e iniciativa popular na elaboração de leis), 2) instrumentos de representação (conselhos consultivos, audiências públicas e pesquisas de opinião) e 3) mediante atuação do terceiro setor.

Os primeiros são menos utilizados, pois envolvem decisões que precisam da concordância de cada indivíduo. Já as práticas de representação são mais comuns na esfera municipal brasileira, na forma de controle comunitário na administração pública realizada pelos conselhos. A vantagem é a participação dos cidadãos que utilizam os serviços públicos, possibilitando agregação de valor na gestão por experiências vivenciadas (NOVELLI, 2006).

Como instrumentos de representação, Avritzer (2009) aponta os conselhos de políticas. Criados para atender aos artigos da Constituição de 1988, que versam sobre a necessidade de participação nas políticas públicas de saúde, assistência social, políticas urbanas e criança e adolescente, os conselhos são modelos de práticas da governança democrática. "Há hoje no Brasil mais de 10 mil conselhos e existem mais conselheiros do que vereadores no país" (AVRITZER, 2009, p. 28).

Criados a partir de leis municipais, os conselhos municipais de saúde são 
exemplos dos conselhos de políticas. Eles advêm de demanda popular apresentada em Conferência Municipal de Saúde, ocasião em que são eleitos os representantes voluntários e não remunerados que atuarão no conselho, com direito à voz e ao voto. As reuniões são mensais e abertas a toda população que, por sua vez, tem direito à voz, mas não a voto. Os conselhos são formados por comissões locais de saúde, as quais estão ligadas às Unidades Básicas de Saúde (Centro de Saúde).

Consoante com as ideias de Haswani (2006) de reconhecimento do cidadão como ator social, sugere-se que, assim como os agentes comunitários de saúde - ACSs - (CARDOSO; NASCIMENTO, 2010), as comissões locais de saúde sejam vislumbradas como elo entre as equipes do PSF e a comunidade numa forma de comunicação além da informação, e também na perspectiva da negociação (SOARES; MONTEIRO, 2012).

Tendo como base o interesse coletivo, Haswani (2007) referencia dois caminhos da comunicação para um Estado emissor: a comunicação pública e a comunicação de solidariedade social. A primeira é dividida em três aspectos principais:

1. Comunicação interna: sua função é fazer circular as informações e motivar os operadores dos setores internos.

2. Comunicação externa destinada aos cidadãos: seu papel é facilitar o diálogo e o acesso dos cidadãos aos serviços públicos e ao Estado, bem como incentivar sua participação nas políticas públicas;

3. Comunicação externa realizada pelos meios de comunicação de massa: sua função é promover a imagem da instituição.
Já a comunicação de solidariedade social tem como objetivo criar consciência a respeito de temas de interesse público com vistas à discussão para solução de problemas, a ser promovida pelo terceiro setor. (HASWANI, 2007).

Segundo Haswani (2006), as reflexões dos pensadores italianos sobre a comunicação pública podem ser, de certa forma, sintetizadas em uma das propostas apresentadas na revisão da autora:

1. Comunicação jurídica-formal: regulamentação jurídica, aplicação de normas, sanções e atividades similares;

2. Comunicação de serviço: comunicação cotidiana que visa informar sobre os serviços disponíveis e como utilizá-los, a fim de garantir o acesso de qualidade, bem como fornecer instruções e informar sobre as regras vigentes;

3. Comunicação administrativa ou comunicação de cidadania: serve para resolver um problema de interesse geral, tendo em vista a realização do modelo de administração partilhada. Exemplos desses problemas são tutela ambiental, da saúde, da previdência, da educação, do emprego, da segurança viária, da ordem pública, da eliminação do lixo, da circulação das pessoas e dos produtos.

Percebe-se que as propostas de Haswani (2006; 2007) partem de uma premissa do Estado emissor no processo de comunicação. Pensando na abordagem proposta por Soares e Monteiro (2012), com base no paradigma relacional proposto por França (2002), sugere-se que as classificações indicadas sejam pensadas de acordo com o contexto de participação e relacionamento 
entre equipes/Unidades Básicas de Saúde e comunidade, o que ocorre em nível local. Assim, na gestão local das organizações de saúde, para a comunicação jurídica-formal, de serviços e administrativa, seriam repensadas as estratégias de comunicação de forma a buscar uma negociação, mais do que transmissão de informações, mesmo que elas em nível macro tenham relevância sabida na comunicação em saúde.

\section{PARTICIPAÇÃO MOBILIZAÇÃO SOCIAL}

POPULAR E

Fossá, Silva e Stasiak (2006) argumentam que uma das grandes problemáticas envolvidas no processo da comunicação pública está relacionada à sua origem, uma vez que ela foi adaptada do formato mercadológico da comunicação privada, portanto, aspectos fundamentais como promover a participação social e a cidadania são muitas vezes esquecidos.

Para Rangel (2008), é importante o papel das áreas de comunicação, educação e mobilização social para fomentar a participação popular. Além disso, possibilita a abertura de espaços de diálogo, onde profissionais, agentes de saúde e população possam, juntos, buscar soluções para os problemas que os afligem. Nesse sentido, conselhos de políticas, comissões locais de saúde e conferências públicas são indicados como alguns exemplos desses espaços com potencial para promover o diálogo.

Para Henriques et al. (2004), a importância da mobilização está em conseguir estimular uma participação maior da população na vida coletiva e, dessa forma, envolvê-la em questões que afligem a sociedade e são de responsabilidade de todos. Peruzzo (2004) afirma ainda que uma questão imprescindível para o exercício da cidadania é o acesso da população aos meios de informação e comunicação.

Para Henriques e outros (2004), a grande tarefa da mobilização é possibilitar a inclusão de sujeitos, criando mecanismos para que eles se envolvam em atividades públicas. A tarefa da comunicação nesses processos "é gerar e manter vínculos entre os movimentos e seus públicos, por meio do reconhecimento da existência e importância de cada um e do compartilhamento de sentidos e de valores" (HENRIQUES et al., 2004, p. 21).

Além disso, Mafra (2006) explica que é necessário que se estabeleça um processo comunicativo em que seja definido o interesse coletivo e entendimentos sejam negociados. Na visão do autor, "a participação num processo de mobilização social é, antes de tudo, criada por uma determinada relação comunicativa estabelecida" (MAFRA, 2006, p. 36). Para Oliveira (2009), a relação com a sociedade implica diversos tipos de interações entre os atores sociais com interesses diferentes, por isso "é fundamental a predisposição para encontrar espaços de diálogo, na tentativa de chegar ao entendimento" (OLIVEIRA, 2009, p. 2).

Para os autores Toro e Werneck (2004, p. 67), "a comunicação tem contribuições importantes e fundamentais no processo de coletivização". Afirmam que o vínculo que se pretende estabelecer com os públicos a fim de gerar uma participação mais ativa deve ser desenvolvido pela ótica relacional do processo de comunicação. Isso prevê um processo circular e global de produção e compartilhamento de sentidos (TORO; 
WERNECK, 2004). Para esse vínculo, a criação de um espaço de debate é importante também na percepção de Oliveira (2003b), que defende o papel da comunicação nesse processo para obter o engajamento da população e, com isso, construir a cidadania. Quanto ao papel da comunicação nesse processo, Vasquez et al. (2003) falam da importância de se manter um fluxo constante de informação e canais de participação desobstruídos. Além disso, é necessário promover ações que propiciem a participação corresponsável, que contribua para o crescimento das pessoas e das organizações.

Tendo em vista a importância do envolvimento da comunidade, Toro e Werneck (2004) explicam que o processo de mobilização passa por dois momentos: o primeiro é o despertar da consciência de ter atitude de mudança; o segundo é a transformação da consciência em disposição para realizar a ação. No contexto da saúde, infere-se que os gestores de organizações públicas de saúde bem como os ACSs e as comissões locais sejam atores ativos nesse processo de mobilização, como elo entre organização e comunidade (CARDOSO; NASCIMENTO, 2010).

$\mathrm{Na}$ visão de Henriques et al. (2004), a vinculação dos públicos passa, também, por um processo evolutivo. $\mathrm{O}$ autor defende que, por meio de intervenções de uma comunicação bem planejada, é possível estabelecer vínculos fortes entre os participantes do projeto de mobilização, que levam à verdadeira mobilização.

Esclarecendo como funciona a participação no processo comunicativo, Henriques et al. (2004) defendem a ideia de que a comunicação adequada à mobilização social seja dialógica, libertadora e educativa. Dialógica no sentido que dever ser compartilhada para promover a troca e não a transferência de saberes. A segunda, libertadora, está relacionada ao que os sujeitos devem juntos problematizar a causa, sem manipulação. E, por fim, a educativa diz respeito ao fato de que a comunicação deve para propiciar espaços onde os sujeitos, por meio do diálogo, produzam e compartilhem conhecimentos e trocas, nos contextos da comunidade.

Considerando essas premissas para a gestão de organizações públicas de saúde, pode-se pensar a participação tanto na implementação quanto na elaboração de políticas locais. No primeiro caso, a gestão pode buscar fomentar a participação na busca de atores multiplicadores de informações e capacitar aqueles atores que têm contato direto com a comunidade. Isso leva a negociar demandas, serviços, normas, regras e assuntos de interesse social mais amplos, como a comunicação jurídico-formal, de serviços e de cidadania (HASWANI, 2006) na perspectiva da negociação, bem como discutir e tomar decisões sobre as campanhas de comunicação do Ministério da Saúde que precisam ser desenvolvidas no local. No caso da elaboração de políticas locais, os espaços dialógicos, como conselhos e conferências, podem se configurar como de discussão e de tomada de decisões quanto às formas e aos conteúdos das campanhas de comunicação fundamentadas no diálogo com a comunidade.

Um desafio apontado por Henriques, Braga e Mafra (2004) para os profissionais que lidam com projetos mobilizadores é manter o interesse dos participantes ao longo do 
tempo. Peruzzo (2004) ressalta a dificuldade de alcançar um grau de participação elevado no Brasil, assim como em outros países latinoamericanos, em razão de suas experiências históricas, que resultam em falta de conscientização política e reprodução de valores autoritários, gerando alienação e conformismo. Portanto, é necessário reconhecer os contextos históricos envolvidos.

\section{METODOLOGIA}

Este artigo é fruto de uma pesquisa qualitativa e descritiva, cujos dados foram coletados em abril de 2011, com a utilização de estudo de caso.

O objeto do estudo foram os Centros de Saúde São Paulo (CSSP) e de Belo Horizonte (Minas Gerais). $\mathrm{O}$ atendimento abrange cinco bairros no entorno. As especialidades de consultas médicas oferecidas são psiquiatra, psicologia, terapia ocupacional, fonoaudiologia e odontologia, além de outros serviços de saúde e prevenção.

O CSSP conta com quatro equipes do Programa Saúde da Família. Cada uma é composta por um médico da família, um enfermeiro, dois auxiliares de enfermagem e seis agentes comunitários de saúde. Possui 85 funcionários e realiza cerca de 700 atendimentos por dia, entre consultas, triagens e atendimentos na farmácia, segundo informações fornecidas pela gerente do Centro.

Os instrumentos de coleta utilizados foram observação direta, entrevistas semiestruturadas, entrevistas estruturadas e grupo focal. Inicialmente, uma observação direta foi feita em dois turnos de funcionamento em dois dias de abril de 2011. Duas pesquisadoras instalarem-se no Centro de Saúde para analisar as ações de comunicação realizadas no Centro de Saúde São Paulo e mapear as possíveis características do relacionamento com os usuários, desde problemas na comunicação até pré-disposição a realizar reclamações diversas.

Elaboraram-se outros dois instrumentos: entrevistas semiestruturadas com cinco gestores públicos e entrevistas estruturadas com 18 usuários. Eles foram selecionados intencionalmente, com base nos seguintes critérios: frequência de utilização do centro, incluindo não usuários, necessidade de atendimento em casa ou deslocamento até - Centro de Saúde e, por fim, localização das residências de forma que houvesse entrevistados de todos os bairros da abrangência do CSSP. Para representar os usuários desse centro, os entrevistados tinham idades entre 14 e 86 anos, com renda familiar de $\mathrm{R} \$ 560,00$ a $\mathrm{R} \$ 2000,00$. A incidência de ocupações foi aposentados, donas de casa, pensionistas, autônomos e comerciantes.

Por fim, foi feito um grupo focal com membros da Comissão local de Saúde do Centro de Saúde São Paulo. Aconteceu em abril de 2011 e entrou como pauta em uma das reuniões periódicas da comissão, para facilitar a presença dos participantes. A Comissão local de Saúde é composta por 14 membros com idades entre 62 a 78 anos, dos quais seis participaram do grupo focal. Vale ressaltar que dois participantes foram fundadores da Comissão, com 42 anos de participação, um atua há dez anos e os outros três ingressaram no grupo há cerca de três anos. Segundo Costa (2008), o grupo focal busca compreender aspectos que são tendências em determinado grupo, normalmente valores, princípios 
e motivações que regem a percepção das pessoas e são colocados na entrevista coletiva. Morgan citado por Costa (2008) postula que, na área de políticas públicas, o grupo focal pode ser utilizado na identificação de problemas, no planejamento, na implementação e na avaliação.

Os dados foram examinados a partir da técnica de análise de conteúdo (BARDIN, 2006), cuja perspectiva qualitativa permite a emergência de categorias após a coleta de dados de forma a não engessar os dados.

\section{RESULTADOS}

Os resultados foram classificados em quatro categorias de acordo com os dados que emergiram do campo, contemplando análises dos gestores, usuários do SUS e membros da Comissão Local de Saúde do CSSP. São elas: paradigma e ações de comunicação, percepção sobre qualidade, compreensão das informações oferecidas pelo Centro de Saúde e participação no processo comunicativo.

\subsection{Paradigma e ações de comunicação}

Na visão da gerente do CSSP, a comunicação direcionada aos usuários é realizada por meio dos agentes comunitários de saúde e da comissão, porém as ações comunicacionais limitam-se à entrega de panfletos e cartazes. A gerente considera a comunicação com os usuários efetiva pelo fato de existir uma comissão, porém todos os entrevistados afirmaram não ter conhecimento de sua existência.

Percebe-se que o modelo de comunicação adotado pelos órgãos públicos em questão gera informação e não troca. Como exemplo, temos o critério de urgência do SUS que foi materializado nas unidades de saúde por meio da classificação de risco por cores. Apesar de ser um ponto essencial de funcionamento do sistema, o gestor reconhece que o não entendimento dessa lógica pode acarretar em questionamentos por parte dos usuários.

[A respeito da classificação de risco por cores] Isso cria em alguns casos uma certa, eu não diria distorção, mas talvez um questionamento (Secretário da Regional Nordeste).

Isso porque o usuário deseja saber os motivos pelos quais o ACS (ou médico) não vai à sua residência, mas sim à casa do vizinho. Ou então, porqueumusuáriochegaantes deoutro, contudo é atendido depois? Esses exemplos são retratos do não compartilhamento de sentidos na comunicação sobre a lógica do SUS. O modelo informacional em questão é encarado pelos gestores como a forma natural de se fazer comunicação, mesmo com essas lacunas.

Para os participantes da Comissão local de Saúde do CSSP, a comunicação é satisfatória somente na campanha da vacinação, pois diversas ferramentas de divulgação são utilizadas nessa época: TV, rádio, anúncio na igreja, faixa na porta do centro de saúde e a comunicação informal entre os membros da Comissão e a comunidade. Assim como os gestores, a comissão considera como comunicação do CSSP a confecção e distribuição de materiais gráficos, na perspectiva de informação (SOARES; MONTEIRO, 2012).

Quando os usuários foram perguntados sobre qual meio utilizam para se informar sobre questões de saúde, como prevenção, doenças, remédios, epidemias, saúde da 
mulher, doenças etc., alguns citaram a TV como meio utilizado. Vale ressaltar que a TV não foi colocada no rol de opções do questionário, sendo um item lembrado naturalmente pelos pesquisados.

Sobre o conhecimento do Programa Saúde da Família, os usuários disseram desconhecer. Eles sabem da existência de agentes comunitários que vão até as residências dos usuários, mas não associam essas visitas ao programa. Alguns entrevistados estabeleceram ligação do programa ao trabalho desenvolvido pelos agentes de saúde. Percebe-se, portanto, que a comunicação realizada para a divulgação do PSF em sua totalidade não consegue sanar todas as dúvidas dos usuários, podendo inclusive gerar questionamentos. Foi possível perceber nas entrevistas uma distorção do PSF ocasionada por uma propaganda televisiva. Segundo o usuário, na TV aparece um médico indo na casa das pessoas. No entanto, a equipe de médicos e enfermeiros só faz visita domiciliar quando há um enfermo acamado que não consegue se deslocar até o centro de saúde.

Observa-se que a comunicação unilateral, no antigo paradigma emissor-receptor, apresentou insuficiências na construção e no compartilhamento do sentido do PSF (FRANÇA, 2002). Para os gestores, o PSF é uma vitrine do SUS, referência, e trouxe melhorias para o sistema. Entretanto, à medida que a comunidade não compreende o que é o PSF, infere-se que ela também não esteja fazendo a assimilação da relação desse programa ao SUS.

Ainda sobre a comunicação como processo constituinte das relações sociais, percebese que os gestores não consideram os funcionários do atendimento como agentes de comunicação, isto é, no pensamento da comunicação como estratégia que guia as ações e decisões. Vale ressaltar que grande parte das reclamações dos usuários está ligada a eles.

Apesar de a gerente do CSSP creditar aos ACSs, ACEs (Agentes Comunitários de Endemias) e à Comissão local de Saúde a atribuição de contato com a comunidade, ela encara isso numa perspectiva de mão única e não de troca.

Para passar para o usuário a ferramenta que a gente tem é a Comissão Local e os agentes comunitários. Às vezes, a gente utiliza [os agentes de] zoonoses também. Aí por exemplo, se vier panfleto a gente distribui panfleto, se vier cartaz a gente cola cartaz. É a maneira que a gente tem (Gerente do CSSP).

Dessa forma, não há um investimento em capacitar e reconhecer os ACSs/ ACEs e a Comissão Local de Saúde, bem como o restante da equipe do Centro de Saúde, como agentes de comunicação dialógica que podem ser facilitadores e multiplicadores de informações.

Para os representantes da comunidade, em alguns momentos, a perspectiva dialógica é considerada importante, como nas falas "O ACS tinha que participar mais" e "[O ACS] Precisa vir participar da comissão e divulgar mais as coisas". Nota-se que a comissão local de saúde percebe o ACS como uma possibilidade de melhoria na comunicação entre o CSSP, a comissão e a comunidade. Além disso, os participantes ressaltaram a questão dos funcionários do atendimento, reconhecendo-os como agentes de comunicação. 
A comunicação no acolhimento é fundamental. $\mathrm{O}$ que falta é comunicação. $\mathrm{O}$ atendimento [dos médicos e enfermeiros] está bom. [...] O usuário reclama, mas tem razão (Grupo Focal).

Observa-se uma percepção de expectativa positiva quanto ao fortalecimento da comunicação dialógica. Entretanto, a comissão local de saúde reconhece que a forma de atendimento dos funcionários pode se tornar uma percepção negativa quanto ao serviço como um todo.

Conforme as classificações de Haswani (2006), a gestão do Centro de Saúde em relação à comunicação considera apenas a comunicação de serviços e em perspectiva de informação. Vale ressaltar que a comunicação jurídica-formal e administrativa/ cidadania não possui destaque no nível local, aquele em que ocorre contato direto com a sociedade e que a negociação nem sempre é considerada no processo de comunicação, mesmo no entendimento de alguns atores como ligação entre equipe e comunidade. A esses atores são designadas algumas funções, como distribuidores de material informativo, mais do que como multiplicadores de informação que ajudam na construção de sentido compartilhado entre atores.

\subsection{Percepção sobre qualidade}

Para os gestores, o estado de Minas Gerais e o município de Belo Horizonte são referências nacionais quando o assunto é saúde, principalmente após a implantação do SUS, conforme trecho destacado:

Com o SUS, os municípios passaram a ter mais autonomia. Hoje, BH é o município mais avançado em saúde no país (Gerente do Distrito Sanitário Nordeste).

Contudo, a crença de que "serviço público é ruim" ainda é muito forte e impacta na percepção. O gestor da Regional Nordeste exemplifica isso com a questão das consultas especializadas.

Mas sempre houve uma crítica muito grande em relação a consultas especializadas na cidade. [...] Uma das justificativas é que demora. Ora, eu me cito como exemplo. Tem consulta da minha mulher que demora seis meses. Marcada [em plano de saúde privado]. E paga convênio. No entanto, demora do mesmo jeito (Secretário da Regional Nordeste).

gestor ressalta ainda que a premissa da má qualidade do SUS é equivocada, pois os procedimentos de saúde mais caros são fornecidos pelo SUS por meio de programas do Governo. De forma geral, os gestores avaliam positivamente o serviço público de saúde prestado pelo SUS, nos âmbitos nacional, estadual e municipal, o que difere da percepção dos representantes comunitários.

$\mathrm{Na}$ abertura da reunião, foi utilizada a técnica de imagens como o intuito de deixála interativa, incentivando a participação de todos desde o início. Foram apresentadas no grupo de foco as seguintes imagens para que os participantes pudessem associálas ao CSSP: uma criança sendo atendida, vacinação, lian gong (ginástica terapêutica e preventiva realizada por meio de movimentos suaves e firmes, tendo como principais benefícios aliviar as tensões musculares, estimular a percepção dos sentidos e trabalhar as articulações para melhorar a mobilidade, a postura e a coordenação motora), roda de reunião entre funcionários, uma enfermeira 
aferindo pressão de um usuário e uma fila. A última foi a imagem escolhida. Percebe-se que a imagem negativa se sobressai entre as demais. Entretanto, em outros momentos da reunião, foi observada uma aceitação de forma natural de alguns problemas geralmente reclamados por usuários, como a questão das consultas especializadas. Eles demonstraram conhecer o processo de marcação desse tipo de consulta e os critérios de urgência estabelecidos pelo SUS para priorização de algumas em detrimento de outras, de acordo com o grau da doença.

Observa-se que, quando o público passa a ter acesso a informações e compreender o processo de funcionamento do Sistema Único de Saúde, há uma possibilidade de maior aceitação quanto à realidade dos centros de saúde. Essa premissa está alinhada às ideias de Ferrari (2008).

Em relação aos usuários, percebe-se que os entrevistados idosos procuram o Centro de Saúde com maior frequência em razão de maiores queixas e problemas de saúde. Eles tenderam a conversar mais sobre atendimento e qualidade dos serviços prestados pelo centro de saúde do que os mais jovens entrevistados.

Corroborando com a questão cultural apontada pelos gestores, o posicionamento dos usuários reflete a posição negativa referente ao sistema público de saúde, pois todos os entrevistados reclamaram dos serviços prestados: demora no atendimento, falta de medicamento e médicos especialistas etc.

Eles marcam todas as pessoas para o mesmo horário, então, quando chegamos, a marcação anterior não vale. $O$ que vale é a ordem de chegada (Usuário entrevistado).

Os usuários apresentaram diversas reclamações sobre o funcionamento do CSSP. Percebe-se que a falta de informação e conhecimento acerca do sistema, como a quem procurar e recorrer, a que local se dirigir, onde conseguir um determinado serviço etc., gera uma percepção negativa do SUS.

Por exemplo, ela veio reclamar comigo: "porque a minha vizinha conseguiu consulta pro dia 11 e eu para o dia 18?". Daí eu pensei: devem ter tantos motivos, tantos motivos. Quer dizer, para eu explicar para toda essa questão é muito complicado. Essa questão da comunicação é muito difícil. Para ela, eu tive que explicar desde o começo, aí ela conseguiu entender (Gerente do CSSP).

Ao serem questionados sobre os principais problemas do centro de saúde, houve um consenso entre as respostas, inclusive entre usuários presentes no CSSP nos dias de observação: demora do atendimento da farmácia após a informatização do sistema de entrega dos medicamentos; falta de paciência e desrespeito dos funcionários com os usuários; atraso no atendimento.

Com relação às qualidades do CSSP, os entrevistados apontaram basicamente os mesmos pontos: atendimento dos médicos e agentes de saúde, serviço de odontologia e o serviço de Posso Ajudar. Isso demonstra a percepção de Lima e Rivera (2009) de que fortes relações entre pessoas que prestam serviços de saúde têm efeito direto na satisfação dos usuários e na sua fidelidade aos serviços.

\subsection{Compreensão das informações oferecidas pelo Centro de Saúde}

Para mais da metade dos usuários 
entrevistados, o meio mais utilizado para se informarem sobre questões de saúde, como prevenção, doenças, remédios, epidemias, saúde da mulher, doenças etc., são os agentes de saúde do CSSP. Outro meio citado por oito respondentes foram amigos e parentes. Os entrevistados que recebem visitas frequentes dos agentes de saúde sugeriram que eles informem mais os usuários sobre os serviços e funcionamento do CSSP.

Ao responderem como é feita a assimilação e compreensão das informações passadas pelo CSSP, alguns entrevistados afirmaram compreender bem todo o conteúdo transmitido, porém, ao serem questionados sobre o funcionamento do centro ou da lógica do SUS, eles não souberam opinar. Outros entrevistados afirmaram que não compreendem de forma adequada as informações, pois não há coerência no que é transmitido aos usuários da unidade básica de saúde:

Todos os dias as informações mudam e aparecem situações diferentes sem que nós sejamos avisados. Diante disso, tudo fica confuso e não conseguimos entender bem como, de fato, funcionam alguns serviços do posto (Usuário entrevistado).

Os agentes de saúde foram citados como facilitadores para compreensão das informações passadas:

Entendo algumas coisas, sim, mas na maioria das vezes procuro as agentes de saúde para tirarem as minhas dúvidas (Usuário entrevistado).

As atendentes, chamadas pelos usuários entrevistados como "moças da janelinha", não são bemavaliadas.Amaioria dos entrevistados ressaltou que elas são impacientes para solucionar dúvidas e fornecer informações. Além disso, observou-se que há um ambiente de excessiva brincadeira entre as atendentes, o que prejudica o atendimento aos usuários, que precisam aguardar a conversa terminar para serem atendidos.

Ao longo da observação, houve uma paralisação de dois dias do sistema público de saúde. Durante esse período, diversos usuários compareceram ao CSSP em busca de atendimento. Ressaltam-se as seguintes falas das atendentes: "Nem a gente sabe direito, como iríamos informar?" ou "É só ver os jornais, gente... tá todo mundo sabendo disso".

Dessa forma, percebe-se um problema na comunicação interpessoal entre o atendimento do CSSP e os usuários. Fato que pode gerar muitas reclamações e fortalecer a cultura de que o serviço público é ruim, mesmo quando há bom atendimento de médicos, enfermeiros e dentistas.

\subsection{Participação no processo comunicativo} Para se avaliar a participação no processo comunicativo, é necessário compreender a participação no contexto mais amplo do Centro de Saúde. Na percepção dos gestores, não somente a Comissão Local do CSSP, como instância de representação, mas a própria comunidade do entorno são participativas. Percebe-se que a gerente do Distrito Sanitário considera como participação o número de pessoas presentes nos eventos promovidos pelos órgãos públicos.

Os gestores consideram que as Comissões Locais de Saúde possuem um papel muito importante na participação popular como 
instância de elaboração de políticas no Conselho e nas Conferências. Acreditam que há necessidade de estimular a participação da comunidade em geral e não somente dos usuários dos centros de saúde e das pessoas que já participam das comissões locais de saúde ou outros conselhos.

Os comerciantes tem que estar lá dentro. 0 empresário. Não é só aquele grupo que às vezes você vai na comissão local e são sempre os mesmos. Às vezes as mesmas pessoas participam de mais de uma Comissão. Ai eu acho que fica pouco representativo (Secretário da Regional Nordeste).

Segundo a Gerente do Distrito Sanitário Nordeste, há vários níveis de participação popular. Para ela, quanto mais carente é uma comunidade, mais participação existe, pois a necessidade dos serviços sociais é maior. Já quando a região se desenvolve, as necessidades locais mudam, e os indivíduos passam a se preocupar mais com questões particulares do que comunitárias. Essa assertiva pode ser considerada paradoxalà medidaque nas regiões mais pobres ou carentes (possivelmente com baixo nível educacional) as pessoas tenham maior dificuldade de expressar suas queixas ou preferências. Por outro lado, em regiões mais desenvolvidas, existem mais grupos com capacidade de mobilização. Entretanto, inferese que a análise da gerente possa estar partindo da percepção apenas dos usuários diretos no Centro de Saúde e não da sociedade como um todo, uma vez que, geralmente, as pessoas de regiões mais abastadas no Brasil não utilizam - SUS, mas sim sistemas privados de saúde. Por isso, não se pode tomar tal interpretação como verdade, e nem é esta uma premissa deste artigo. A construção de sentido que a gerente fez parte de sua vivência, o que torna sua observação importante por fazer parte da realidade social em questão.

De acordo com os gestores, o contexto histórico de cada comunidade interfere no nível de participação popular. $O$ CSSP surgiu em razão da demanda da comunidade local, portanto os gestores entendem que a participação deveria ser efetiva, justamente por essa iniciativa ter partido da própria população.

Ao contrário dos gestores, a Comissão Local do CSSP afirma que a comunidade tem pouca ou nenhuma participação. Para os membros, os fatores resultantes dessa situação são diversos, como não haver nenhum tipo de remuneração, falta de vontade e descrédito.

No grupo focal, ressaltou-se que a participação da comunidade está diretamente relacionada ao sucesso das atividades da comissão, como nos casos de bairros vizinhos que conseguem realizar grandes obras, modificações e melhorias. Entretanto, os participantes afirmaram que as comissões não se comunicam entre si, em razão das disputas que possam ocorrer por melhorias em cada comunidade por meio de busca de votos no Orçamento Participativo. Por fim, os membros da Comissão Local do CSSP e os gestores concordam no seguinte aspecto:

A comunidade não sabe do poder que ela tem. Uma comunidade organizada coloca um município para frente (Gerente do Distrito Sanitário Nordeste).

O povo só sabe reclamar! Poderíamos ter coisas melhores! Eles não sabem a força que uma associação de bairro tem junto ao poder público. Quem luta, alcança 
(Grupo Focal).

Apesar de os gestores entenderem e valorizarem o papel das comissões locais de saúde, todos os entrevistados afirmaram desconhecer a comissão do CSSP. Além disso, nunca participaram de nenhuma Organização Não Governamental (ONG), projeto social ou associação comunitária por falta de tempo e informação sobre procedimentos e funcionamentos deles. Ao serem questionados sobre o desejo de participar de projetos que envolvem a comunidade, os entrevistados afirmaram não ter vontade de se envolver nesse tipo de atividade e alguns falaram sobre a falta de informação sobre isso.

Ao serem questionados sobre como podem ajudar na comunidade em questões de saúde, alguns entrevistados não souberam opinar, pois acreditam que esse papel deve ser realizado pela prefeitura e pelo Centro de Saúde. Outros acreditam que participam ao passar aos vizinhos informações que já receberam sobre prevenção de doenças e epidemias.

Percebe-se, portanto, que existem diferentes construções de sentido para o termo "participação popular". Mesmo tendo pontos em comum, não se observa um processo de comunicação, em seu sentido constituinte, que vise à negociação e à troca. Em sentido estratégico, percebe-se que há intenção de se valer da Comissão como contato com a comunidade para obter informações. Contudo, ressalta-se novamente a necessidade de se rever os paradigmas sobre os quais a comunicação é desenvolvida nas organizações públicas de saúde, pois a Comissão deve ser inserida não somente na execução de ações esporádicas, mas também em um sistemático processo que esteja atento às demandas da comunidade e dos usuários ao mesmo tempo em que esteja integrado às ações do Centro de Saúde. Para mudar o paradigma informacional (emissor-receptor) para o relacional (interagentes), é necessário que os atores discutam seus papeis e sejam capacitados como interlocutores, além de se abrirem os canais de comunicação dispostos a negociar e trocar informações relevantes tanto para a comunidade quanto para a organização, não deixando de observar os interesses dos representantes da Comissão Local de Saúde nesse processo.

\section{CONSIDERAÇÕES FINAIS}

O propósito deste artigo é levar os leitores a compreender como ocorrem os processos de comunicação entre a organização que presta serviços públicos de saúde e seus usuários. Embora se refira ao retrato de apenas um centro de saúde do município, com características particulares e especificidades, acredita-se que este estudo contribui para a discussão da comunicação como processo tanto constituinte quanto estratégico nas organizações públicas. Além disso, pode-se estender as contribuições para a formulação e implementação de políticas públicas, uma vez que as demandas da população podem ser enxergadas e debatidas em real contexto, por via da comunicação dialógica.

É válido destacar que se buscou compreender a comunicação em duas dimensões principais: como 1) processo estratégico, no qual há ações intencionais que visam guiar ações e decisões em linhas gerais nas organizações; e como 2) constitutiva dos processos de relação social. O primeiro item refere-se basicamente a atividades e ações de comunicação 
planejadas e executadas pela organização, enquanto o segundo é uma dimensão inerente ao social. A segunda perspectiva está relacionada também à forma que se percebe a comunicação em termos de paradigma: informacional ou dialógico-relacional, por exemplo. Essa visão da comunicação enseja tipos de ações estratégicas diferentes, como distribuição de panfletos para divulgação de serviços pelo ACS ou ação comunicativa dos ACSs e representantes da Comissão Local de Saúde, que visem à troca e à negociação. Dessa forma, muitas vezes, eles estão imbricados, pois uma visão pode interferir na outra.

De acordo com os resultados, pôde-se concluir que o modelo de comunicação percebido por meio das práticas dos órgãos públicos em questão é o informacional, baseando-se em comunicação de massa. Modelo este que, apesar de funcionar bem em casos como campanhas nacionais de saúde, apresenta inadequação à realidade do CSSP, conforme achados da pesquisa. Acredita-se que a não capacitação para o uso de informações e serviços pode explicar parte dessas distorções no processo de comunicação.

Foi possível perceber também que os gestores entendem a Comissão Local de Saúde como importante canal de comunicação com a comunidade, embora existam lacunas nessa relação. O CSSP tem uma expectativa quanto à essa comissão: que ela seja a ligação com a comunidade. Entretanto, observou-se que as pessoas não têm conhecimento do que é, muito menos, para que ela serve. Ou seja, a Comissão Local de Saúde não tem ainda o papel desejado pelo CSSP. Já a comissão, que tem a mesma visão de comunicação sob a perspectiva informacional, espera que o CSSP repasse informações e materiais informativos em tempo hábil, o que nem sempre ocorre.
Constatou-se que, na percepção dos usuários, a comunicação via Agente Comunitário de Saúde tem relevância e que, a partir do momento que o público passa a ter acesso a informações e compreender o processo, ocorre maior aceitação.

Acredita-se que a comunicação unilateral utilizada no PSF, no antigo paradigma emissor-receptor, teve insuficiência em sua construção e seu compartilhamento. Para os gestores, o PSF é uma vitrine do SUS, referência, e trouxe melhorias para o sistema. Entretanto, à medida que a comunidade não compreende o que é o programa, infere-se que ela também não esteja fazendo a relação do PSF como elemento fundamental para o SUS.

As diferentes visões sobre a participação popular da comunidade do entorno do CSSP são um exemplo de diversos compartilhamentos e construções de sentido. Para os gestores, que entendem a participação como a presença de representantes da comunidade nas reuniões e conferências, a comunidade é participativa. Contudo, para a Comissão Local de Saúde, que tenta mobilizar a comunidade principalmente para a causa da administração do CSSP, a comunidade não é participativa. Os usuários alegaram não participar desse tipo de atividade e até desconhecem quem o faz.

Este artigo abre precedentes para outros estudos dentro da área de administração pública, comunicação e saúde. De forma interdisciplinar, a mobilização social pode ser trabalhada sob outras perspectivas, além da comunicação. Outro estudo agregador dessa temática é avaliar como os funcionários dos centros de saúde e 
ACSs compreendem a comunicação na saúde e quais as implicações do estudo na comunicação geradas na gestão de políticas públicas. Além disso, sugere-se que haja continuidade das discussões sobre "Comunicação pública" e "Comunicação dialógica" no Brasil e que as questões apresentadas sejam aprofundadas para potencializar as ações das organizações públicas.

Com esta pesquisa, percebe-se a necessidade de reestruturar alguns aspectos comunicacionais quanto ao relacionamento do CSSP com seus usuários. Defende-se que a coordenação das ações de saúde seja vista de forma dialógica e relacional, com participação dos atores como interagentes, além da obtenção de ferramentas e instrumentos básicos de comunicação. Fica evidente também a necessidade de reconhecer os funcionários do atendimento como importante canal de comunicação com o usuário para o desenvolvimento de estratégias de melhorias na comunicação interpessoal.

Defende-se ainda que os integrantes da Comissão Local de Saúde sejam qualificados como agentes multiplicadores, visando ao exercício da função proposta pela Constituição de forma efetiva e eficiente, para estimular a participação popular. É necessário que eles conheçam suas possibilidades de atuação dentro da comunidade, dentro do CSSP e junto aos outros órgãos envolvidos no âmbito da saúde.

\section{REFERÊNCIAS}

AVRITZER, L. Sociedade civil e participação no Brasil democrático. In:AVRITZER, L. (Org.)
Experiências nacionais de participação social. São Paulo: Cortez, 2009.

BELO HORIZONTE. Prefeitura de Belo Horizonte. Portal da PBH. 2010. Disponível em: www.pbh.gov.br. Acesso em: 26 set. 2010.

BRASIL. Ministério Da Saúde. Entendendo o SUS. Brasília: Ministério da Saúde, 2006. Disponível em: <http://portal.saude.gov.br/ portal/arquivos/pdf/cartilha_entendendo_o_ sus_2007.pdf>. Acesso em: 22 set. 2010.

CORDEIRO, S., CORNWALL, A., DELGADO, N. A luta por participação e controle social em um conselho municipal de saúde. In: ROMANO, J., ANDRADE, M., ANTUNES, M. (Orgs.). Olhar crítico sobre participação e cidadania: a construção de uma governança democrática e participativa a partir do local. 1. ed. São Paulo: Expressão Popular: Action Aid Brasil, 2007.

FERRARI, M. A. Teorias e Estratégias de Relações Públicas. In: KUNSCH, M. M. K. (Org.). Gestão Estratégica de Comunicação Organizacional e Relações Públicas. São Caetano do Sul: Difusão, (2008).

FOSSÁ, M. I., SILVA, J. Q., STASIAK, D. Comunicação social em instituições públicas: estudo de caso do Poder Legislativo de Santa Maria - RS. UNIRevista, 2006, 1 (3).

FRANÇA, V Paradigmas da comunicação: conhecer o quê? In: MOTTA, L. G., WEBER, M. H., FRANÇA, V., PAIVA, R. (Orgs.). Estratégias e culturas da comunicação. Brasília: Editora Universidade de Brasília, 2002.

HASWANI, M. F. Comunicação Governamental: em busca de um alicerce 
teórico para a realidade brasileira. São Paulo, Organicom, 2006, 3 (4), 190 p.

HASWANI, M. (2007). Comunicação pública e as novas dimensões para as relações públicas. In KUNSCH, M. M., KUNSCH, W. L. (Orgs.). Relações Públicas Comunitárias: a comunicação em uma perspectiva dialógica e transformadora. São Paulo: Summus.

HENRIQUES, M., BRAGA, C., COUTO E SILVA, D., MAFRA, R. Relações Públicas em projetos de mobilização social: funções e características. In: HENRIQUES, Márcio (Org.). Comunicação e estratégias de mobilização social. Belo Horizonte: Autêntica, 2004.

HENRIQUES, M., BRAGA, C., MAFRA, R. O planejamento da comunicação para a mobilização social: em busca da coresponsabilidade. In HENRIQUES, M. (Org.). Comunicação e estratégias de mobilização social. Belo Horizonte: Autêntica, 2004.

$\mathrm{KUNSCH}, \mathrm{M}$. Planejamento de Relações Públicas na Comunicação Integrada. São Paulo: Summus, 2003.

KUNSCH, M. Dimensões e perspectivas das relações públicas comunitárias. In $\mathrm{KUNSCH}$, M., KUNSCH, W. L. (Orgs.). Relações Públicas Comunitárias: a comunicação em uma perspectiva dialógica e transformadora. São Paulo: Summus, 2007.

MAFRA, R. Entre o espetáculo, a festa e a argumentação: mídia, comunicação estratégica e mobilização social. Belo Horizonte: Autêntica, 2006.

MATOS, H. H. G. Comunicação Política e Comunicação Pública. São Paulo, Organicom, 2006, 3 (4), 190p.
NOVELLI, A. L. C. R. O papel institucional da Comunicação Pública para o sucesso da governança. São Paulo, Organicom, 2006, 3 (4), 190p.

OLIVEIRA, I. L. Novo sentido da comunicação organizacional: construção de um espaço estratégico. XXVI Congresso Anual em Ciência da Comunicação. Anais. Belo Horizonte/MG, 2003.

OLIVEIRA, I. L. Espaços dialógicos e relacionais nas organizações e sua natureza ético-política. In: KUNSCH, M. M. K. (Org.). Comunicação Organizacional: linguagem, gestão e perspectivas. São Paulo: Saraiva, 2009, v. 2, p. 321-332.

OLIVEIRA, I. L., PAULA, M. A. Processos e estratégias de comunicação no contexto das organizações. In: OLIVEIRA, I. L., LIMA, F. Propostas conceituais para a comunicação no contexto organizacional. São Caetano do Sul: Difusão, 2012.

OLIVEIRA, M. J. Gestão pública, comunicação e cidadania: o caso da Prefeitura Municipal de Campinas. IN: Congresso Anual em Ciência da Comunicação, XXVI, Belo Horizonte. Anais. Belo Horizonte, 2003b.

PERUZZO, C. M. K. Comunicação nos movimentos populares: a participação na construção da cidadania. 3. ed. Petrópolis: Vozes, 2004.

RANGEL, M. L. Dengue: educação, comunicação e mobilização na perspectiva do controle - propostas inovadoras. Interface - Comunicação, saúde e 
educação, 2008, 12 (25), p. 433-441.

SOARES, A. T., MONTEIRO, L. O contexto das organizações: uma leitura sobre suas configurações e seus processos comunicacionais. In: OLIVEIRA, I. L., LIMA, F. Propostas conceituais para a comunicação no contexto organizacional. São Caetano do Sul: Difusão, 2012.

TORO, J. B., WERNECK, N. M. Mobilização social: um modo de construir a democracia e a participação. Belo Horizonte: Autêntica, 2004.

VASQUEZ, M. L., SILVA, M. R., CAMPOS E., ARRUDA, I. DINIZ, A., VERAS, I., PEREIRA, A. P. Participação social nos serviços de saúde: concepções de usuários e líderes comunitários em dois municípios do Nordeste do Brasil. Caderno de Saúde Pública, Rio de Janeiro, 2003, 19 (2), p.579-591. 